\title{
Factors affecting physical activity among prediabetic women: the application of the Theory of Planned Behavior
}

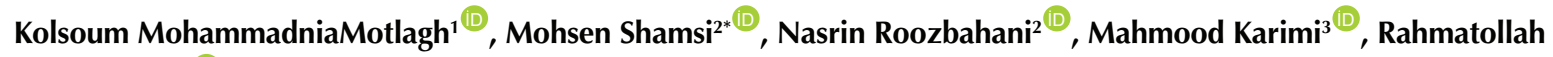 \\ Moradzadeh $^{(\mathbb{D}}$ \\ ${ }^{1}$ Master of Health Education, Student Research Committee, School of Health, Arak University of Medical Sciences, Arak, Iran \\ ${ }^{2}$ Associate Professor, Department of Health Education and Health Promotion, School of Health, Arak University of Medical \\ Sciences, Arak, Iran \\ ${ }^{3}$ Associate Professor, Department of Public Health, School of Nursing and Midwifery, Saveh University of Medical Sciences, \\ Arak, Iran \\ ${ }^{4}$ Associate Professor, Department of Epidemiology, School of Health, Arak University of Medical Sciences, Arak, Iran
}

\begin{abstract}
Background and aims: Prediabetic individuals are more at risk for developing diabetes mellitus (DM). Physical activity (PA) is a significant factor contributing to health maintenance and promotion. This study aimed to assess the factors affecting PA among prediabetic women based on the Theory of Planned Behavior (TPB).

Methods: This cross-sectional study was conducted in 2019 on 100 prediabetic women selected from comprehensive healthcare centers in Arak, Iran. A demographic questionnaire, a TPB-based questionnaire, and Godin-Shephard Leisure-Time Physical Activity Questionnaire were used for data collection. Data were analyzed through the Spearman's correlation analysis and the linear regression analysis with the backward method.

Results: The mean score of PA was $0.56 \pm 0.8$ (in the possible range of $0-2$ ). Around $61 \%$ of participants had limited PA, $16 \%$ of them had moderate PA, $19 \%$ of them had adequate PA and $4 \%$ no response. Perceived behavioral control explained $5.5 \%$ of the variance of the PA behavior.

Conclusion: Given the significant effects of perceived behavioral control on PA, TPB-based educations may be helpful in promoting PA among prediabetic women.

Keywords: Prediabetes, Physical activity, Theory of planned behavior, Women
\end{abstract}

*Corresponding Author: Mohsen Shamsi, School of Health, Arak University of Medical Sciences, Arak, Iran Telefax: +98 (86) 33684615

Email: dr.shamsi@arakmu. ac.ir, Mohsen_shamsi1360@ yahoo.com

Received: 16 August 2020 Accepted: 21 September 2020 ePublished: 30 March 2021

\section{Introduction}

Diabetes mellitus (DM) is a chronic illness caused by the lack or the reduced effectiveness of insulin and is associated with altered metabolism of carbohydrates, lipids, and proteins (1). Diabetes is a metabolic, multifactorial disorder, which is characterized by chronic high blood sugar or hyperglycemia and is caused by impaired insulin secretion or action or both of them. Diabetes is also called silent epidemic and is considered as a major general hygiene problem which accounts for $9 \%$ of all deaths in the world type $2 \mathrm{DM}$ is the most prevalent metabolic disorder (2). The World Health Organization reported that there were 422 million people with DM in the world in 2017 and the International Diabetes Federation estimated that the number of people with prediabetes will reach 471 million by $2035(3,4)$. Around $70 \%$ of people with prediabetes will also eventually develop DM (5). A recent systematic review and meta-analysis reported the high prevalence of metabolic disorders among women and people in urban areas in Iran (2). DM is a leading cause of blindness, renal failure, myocardial infarction, cerebrovascular accidents, limb amputation, and death. In 2016, DM directly caused around 1.6 million deaths in the world (5).

DM treatments cannot prevent all DM-associated complications. Therefore, prevention of DM and even prediabetes is preferred (6). Lifestyle is a significant factor affecting health in all age groups (7). The World Health Organization states that lifestyle modification helps prevent type $2 \mathrm{DM}$ by almost $90 \%$ (8). Physical activity (PA) is an important component of lifestyle (7). A study showed that the level of PA among women was lower than men (9).

Human behaviors are affected by many different factors. Recognizing the factors affecting lifestyle behaviors is necessary for effective behavior modification. Behaviorrelated models and theories are useful for accurate behavior assessment (10). There are many theories concerning health behavior, however, we must be very careful in selecting them. One of these theories is the Theory of Planned Behavior (TPB). TPB is one of the most important theories for behavior modification. TPB is used to determine and understand the effect of environmental and individual factors on a behavior. Since the theory measures both direct behavior and intention (they are

(C) 2021 The Author(s); Published by Shahrekord University of Medical Sciences. This is an open-access article distributed under the terms of the Creative Commons Attribution License (https://creativecommons.org/licenses/by/4.0), which permits unrestricted use, distribution, and reproduction in any medium, provided the original work is properly cited. 
closely related to each other), it can be used to improve the preventive behavior of diabetics and individuals' behavior through measurement of the intention $(11,12)$.

The present study aimed to assess the factors affecting PA among prediabetic women based on TPB.

\section{Methods \\ Design and participants}

This cross-sectional study was conducted in 2019. Participants were 100 prediabetic women selected from comprehensive healthcare centers in Arak, Iran. For sampling, Arak city was divided into five hypothetical areas based on the socioeconomic characteristics of its people and then, two healthcare centers were randomly selected from each area. After that, eligible women were recruited to the study from the selected centers through purposive sampling. Inclusion criteria were an age of 3060 years, basic literacy skills, agreement for participation, and no pregnancy. The only exclusion criterion was unwillingness to remain in the study.

\section{Data collection instrument}

Data were collected using a demographic questionnaire, a TPB-based questionnaire, and the Godin-Shephard Leisure-Time Physical Activity Questionnaire. The TPBbased questionnaire had four main dimensions on attitude (six items), subjective norms (three items), perceived behavioral control (four items), and behavioral intention (one item). The items were scored on a five-point scale from 1 ("Completely disagree") to 5 (“Completely agree"). The possible total score of the dimensions was 1-5 (13).

The Godin-Shephard Leisure-Time Physical Activity Questionnaire is a valid instrument for PA assessment. Participants were asked to report the average time and the frequency of their mild, moderate, and intense weekly PA in the past month. Their answers were used to calculate the metabolic equivalent of task (MET) for PA. MET is a ratio for the amount of oxygen consumed per kilogram $(\mathrm{kg})$ of body weight per minute at rest. On average, one MET is 3.5 milliliters of oxygen per kg of body weight. For calculating MET ratio, the amounts of mild, moderate, and intense physical activities were multiplied by 3,5 , and 9, respectively. MET-Time values were interpreted as follows: less than 14: immobility or limited PA (scored zero); 14-23: moderate PA (scored 1); and 24 and more: adequate PA (scored 2).

\section{Data analysis}

Study data were analyzed via the SPSS software (v. 26). The Kolmogorov-Smirnov test revealed that the study variables had non-normal distribution. The Spearman's correlation analysis and the linear regression analysis with the Backward method were used for data analysis.

\section{Results}

In total, 100 prediabetic women participated in the study. Most participants were married (96\%) and housewife
(90\%) and the mean and the range of their age were $47.40 \pm 7.64$ and $31-59$ years, respectively (Table 1 ). The prevalence rates of hypertension, hyperlipidemia, and hypothyroidism among participants were 15\%,14\%, and $12 \%$, while $16 \%$ of participants simultaneously suffered from comorbidities of these problems and $43 \%$ of them did not report these problems. Moreover, musculoskeletal problems were the most prevalent health problem among participants with a prevalence of $54 \%$.

The mean score of PA was $0.56 \pm 0.8$ in the possible range of $0-2$ (Table 2). Around $61 \%$ of participants reported limited PA, $16 \%$ of them reported moderate PA, $19 \%$ of them reported adequate PA and $4 \%$ no response. Perceived behavioral control had significant relationships with attitude $(P=0.001)$, behavioral intention $(P=0.002)$, and PA $(P=0.034)$. Moreover, behavioral intention had

Table 1. Participants' characteristics

\begin{tabular}{|c|c|c|}
\hline \multicolumn{2}{|l|}{ Characteristics } & $N(\%)$ or Mean $\pm S D$ \\
\hline \multirow{3}{*}{ Marital status } & Single & $2(2)$ \\
\hline & Married & $96(96)$ \\
\hline & Divorced & $2(2)$ \\
\hline \multirow{5}{*}{ Educational level } & Primary & $39(39)$ \\
\hline & Guidance school & $16(16)$ \\
\hline & High school & $2(2)$ \\
\hline & Diploma & $32(32)$ \\
\hline & University & $10(10)$ \\
\hline \multirow{3}{*}{ Employment status } & Housewife & $90(90)$ \\
\hline & Employed & $6(6)$ \\
\hline & Retired & $3(3)$ \\
\hline \multirow{2}{*}{ Medication intake } & Yes & $16(16)$ \\
\hline & No & $82(82)$ \\
\hline \multirow{2}{*}{ Cigarette smoking } & Yes & $1(1)$ \\
\hline & No & $99(99)$ \\
\hline \multirow{2}{*}{ Waterpipe tobacco smoking } & Yes & $2(2)$ \\
\hline & No & $96(96)$ \\
\hline \multicolumn{2}{|l|}{ Age $(y)$} & $47.40 \pm 7.64$ \\
\hline \multicolumn{2}{|l|}{ Systolic blood pressure $(\mathrm{mm} \mathrm{Hg})$} & $115.37 \pm 16.12$ \\
\hline \multicolumn{2}{|c|}{ Diastolic blood pressure $(\mathrm{mm} \mathrm{Hg})$} & $75.85 \pm 11.82$ \\
\hline \multicolumn{2}{|l|}{ Fasting blood sugar (mg/dL) } & $107.59 \pm 6.56$ \\
\hline \multicolumn{2}{|l|}{ Body mass index $\left(\mathrm{kg} / \mathrm{m}^{2}\right)$} & $30.96 \pm 4.33$ \\
\hline \multicolumn{2}{|l|}{ Waist circumference (cm) } & $97.35 \pm 9.53$ \\
\hline \multicolumn{2}{|l|}{ Duration of prediabetes (days) } & $417.40 \pm 672.52$ \\
\hline
\end{tabular}

Table 2. The mean scores of the TPB constructs and the PA behavior

\begin{tabular}{lccc}
\hline Constructs & Mean \pm SD & Possible range & Range \\
\hline Attitude & $4.46 \pm 0.5$ & $1-5$ & $1.83-5$ \\
Subjective norms & $4.42 \pm 0.66$ & $1-5$ & $2.67-5$ \\
Perceived behavioral control & $3.34 \pm 0.78$ & $1-5$ & $1-5$ \\
Behavioral intention & $4.18 \pm 1.21$ & $1-5$ & $1-5$ \\
Behavior (PA) & $0.56 \pm 0.8$ & $0-2$ & $0-2$ \\
\hline
\end{tabular}


Table 3. The coefficients of the pairwise correlations of the study variables

\begin{tabular}{lccc}
\hline Variables & Attitude & Subjective norms & Perceived behavioral control \\
\hline Attitude & - & - & Behavioral intention \\
Subjective norms & $r=0.130$ & - & - \\
& $P=0.199$ & & - \\
Perceived behavioral control & $r=0.337$ & $r=0.070$ & $r=0.302$ \\
& $P=0.001$ & $r=0.374$ & $P=0.002$ \\
Behavioral intention & $r=0.484$ & $P=0.000$ & $r=0.216$ \\
& $P=0.000$ & $r=0.044$ & $P=0.034$ \\
Behavior (PA) & $r=-0.024$ & $P=0.667$ & $P=0.110$ \\
\hline
\end{tabular}

significant relationships with attitude $(P<0.001)$ and subjective norms $(P<0.001)$ (Table 3$)$. The results of the linear regression analysis through the Backward method revealed that perceived behavioral control predicted 5.5\% of the total variance of PA.

\section{Discussion}

This study assessed the factors affecting PA among prediabetic women based on TPB. Findings showed that perceived behavioral control significantly predicted PA. Two previous studies also reported the same finding (1315). However, two other studies reported subjective norms and behavioral intention as the most important predictors of regular PA among patients receiving hemodialysis (16) and college students (17). This contradiction is probably due to the difference among the studies respecting their target population.

Study findings also showed that although the mean score of perceived behavioral control was at moderate level, it was less than the mean scores of the other constructs of TPB. This finding denotes engagement in PA during normal life conditions and non-adhere to PA in conditions such as illness, holidays, and busy life. Moreover, study findings revealed that the most prevalent health problem affecting PA was musculoskeletal problems. These problems are exacerbated by PA and hence, can act as a barrier to PA. In addition, we found that participants were unable to actively engage in outdoor PA such as walking due to their household responsibilities such as childrearing. A former study also reported the same finding (13).

Although the relationship between attitude and PA was not significant, the significant relationship of perceived behavioral control with attitude and PA denotes that attitude can indirectly affect PA through perceived behavioral control. Moreover, attitude had significant positive relationship with behavioral intention. A previous study also reported that attitude and subjective norms were significant predictors of behavioral intention for PA (18).

Our findings also showed that the highest dimensional mean score was related to the attitude dimension, denoting participants' positive attitude towards PA. Two former studies also reported the same finding $(18,19)$. Moreover, study findings revealed that $61 \%$ of participants had low levels of PA. In line with this finding, a former study also reported that $61.3 \%$ of women had limited PA (20). Given the positive PA-related attitude among women and the significant relationship of attitude with behavioral intention, healthcare authorities can develop strategies to improve women's PA-related attitude and behavioral intention in order to promote their PA.

One of the limitations of the present study was that most participants had low levels of literacy. Moreover, their health-related data were not available through a comprehensive national system and hence, we had problems in identifying eligible participants.

\section{Conclusion}

This study shows that although the mean scores of most TPB constructs are high, the mean score of PA is not high and the theory cannot confidently predict PA. It seems that factors such as limited perceived threat of the health problems associated with limited PA as well as barriers to PA (including time limitation, expensiveness of going to gyms, and limited motivation) can affect women's engagement in PA.

\section{Authors' contribution}

All authors had significant contribution to the study and the manuscript.

\section{Conflict of Interests}

The authors declare no conflict of interests.

\section{Ethical Approval}

The Ethics Committee of Arak University of Medical Sciences, Arak, Iran, approved this study (code: IR.ARAKMU. REC.1398.073). Withdrawal from the study was voluntary, study data were managed confidentially, participants were informed about the study aim, and informed consent was obtained from all participants.

What does this paper contribute to the wider global clinical community?

- Perceived behavioral control is a significant predictor of the physical activity behavior among prediabetic women.

- Given the significant effects of perceived behavioral control on physical activity, educations based on the Theory of Planned Behavior may be helpful in promoting physical activity among prediabetic women. 


\section{Funding/Support}

This study was financially supported by the Research and Technology Administration of Arak University of Medical Sciences, Arak, Iran.

\section{Acknowledgement}

This article was extracted from a Master's thesis in Health Education approved by the Research and Technology Administration of Arak University of Medical Sciences, Arak, Iran. We are grateful to the above-mentioned administration as well as all women who participated in the study.

\section{References}

1. Ikezaki H, Ai M, Schaefer EJ, Otokozawa S, Asztalos BF, Nakajima K, et al. Cardiovascular disease prevalence and insulin resistance in the Kyushu-Okinawa Population Study and the Framingham Offspring Study. J Clin Lipidol. 2017;11(2):348-56. doi: 10.1016/j. jacl.2017.01.014.

2. Mehdikhani S, Gohari MR, Banazade Z. Determining factors affecting fasting blood sugar in patients with type 2 diabetes using Copula functions. Razi J Med Sci. 2014;21(122):1-8. [Persian].

3. Anonymous. Diabetes. WHO; 2018 [updated 30 Oct 2018]. http://www.who.int/news-room/fact-sheets/ detail/diabetes.

4. International Diabetes Federation (IDF). IDF Diabetes Atlas. 6th ed. Brussels, Belgium: IDF; 2013.

5. Heianza Y, Hara S, Arase $Y$, Saito K, Fujiwara K, Tsuji $\mathrm{H}$, et al. HbA1c $5 \cdot 7-6 \cdot 4 \%$ and impaired fasting plasma glucose for diagnosis of prediabetes and risk of progression to diabetes in Japan (TOPICS 3): a longitudinal cohort study. Lancet. 2011;378(9786):14755. doi: 10.1016/s0140-6736(11)60472-8.

6. Perreault L, Pan Q, Mather KJ, Watson KE, Hamman RF, Kahn SE. Effect of regression from prediabetes to normal glucose regulation on long-term reduction in diabetes risk: results from the Diabetes Prevention Program Outcomes Study. Lancet. 2012;379(9833):2243-51. doi: 10.1016/s0140-6736(12)60525-x.

7. Reunamo J, Saros L, Ruismäki H. The amount of physical activity in Finnish day care. Procedia Soc Behav Sci. 2012;45:501-6. doi: 10.1016/j.sbspro.2012.06.587.

8. American Diabetes Association. Standards of medical care in diabetes-2017 abridged for primary care providers. Clin Diabetes. 2017;35(1):5-26. doi: 10.2337/cd16-0067.

9. Santos R, Santos MP, Ribeiro JC, Mota J. Physical activity and other lifestyle behaviors in a Portuguese sample of adults: results from the Azorean Physical Activity and Health Study. J Phys Act Health. 2009;6(6):750-9. doi: 10.1123/jpah.6.6.750.

10. Conner M. Theory of planned behavior. In: Tenenbaum
G, Eklund RC, eds. Handbook of Sport Psychology. Wiley; 2020. p. 3.

11. Si H, Shi JG, Tang D, Wu G, Lan J. Understanding intention and behavior toward sustainable usage of bike sharing by extending the theory of planned behavior. Resour Conserv Recycl. 2020;152:104513. doi: 10.1016/j.resconrec.2019.104513.

12. Fatahi A, Doosti-Irani A, Cheraghi Z. Prevalence and incidence of metabolic syndrome in Iran: a systematic review and meta-analysis. Int J Prev Med. 2020;11:64. doi: 10.4103/ijpvm.IJPVM_489_18.

13. Rahmati-Najarkolaei $F$, Pakpour AH, Saffari $M$, Hosseini MS, Hajizadeh F, Chen $\mathrm{H}$, et al. Determinants of lifestyle behavior in Iranian adults with prediabetes: applying the theory of planned behavior. Arch Iran Med. 2017;20(4):198-204.

14. Godin G. The Godin-Shephard leisure-time physical activity questionnaire. The Health \& Fitness Journal of Canada. 2011;4(1):18-22. doi: 10.14288/hfjc.v4i1.82.

15. Dashtian M, Eftekhar-Ardebili H, Karimzadeh-Shirazi K, Shahmoradi M, Azam K, Piraee E. The effect of educational intervention, based on the theory of planned behavior, on medication adherence and physical activity in patients with type 2 diabetes mellitus. J Health Syst Res. 2018;14(1):41-7. doi: 10.22122/jhsr.v14i1.3201. [Persian].

16. Dormanesh B, Daryabeigi R, Hadi S, Sepahvand V, Sarkhosh Tonekaboni A. Application of the theory of planned behavior in dietary and physical activity behaviors among hemodialysis patients visiting army hospitals. Pajouhan Scientific Journal. 2018;16(2):1927. doi: 10.21859/psj.16.2.19. [Persian].

17. Moeini B, Jalilian F, Jalilian M, Barati M. Predicting factors associated with regular physical activity among college students applying BASNEF model. Avicenna J Clin Med. 2011;18(3):70-6. [Persian].

18. Saber F, Shanazi H, Sharifrad G. The survey of theory of planned behavior constructs regarding girl student's physical activity in Naein Payame Noor University in 2012. J Health Syst Res. 2013;9(9):1014-21. [Persian].

19. Solhi M, Zinatmotlagh F, Karimzadeh Shirazi K, Taghdisi $\mathrm{MH}$, Jalilian F. Designing and implementing educational program to promote physical activity among students: an application of the theory of planned behavior. Ofogh-e-Danesh. 2012;18(1):45-52. [Persian].

20. Bayrami R, Didarloo A, Asadinejad A. Prediction of physical activity based on the BASNEF model constructs during preconception period among women referred to Uremia health centers. J Hayat. 2020;26(1):105-17. [Persian]. 